\title{
Decadal Variations in the Relationship between the Western Pacific Subtropical High and Summer Heat Waves in East China
}

\author{
QI LIU \\ School of Atmospheric Sciences, and Institute for Climate and Global Change Research, and Jiangsu Collaborative \\ Innovation Center for Climate Change, Nanjing University, Nanjing, China \\ TIANJUN ZHOU \\ LASG, Institute of Atmospheric Physics, Chinese Academy of Sciences, and University of Chinese Academy \\ of Sciences, Beijing, and Jiangsu Collaborative Innovation Center for Climate Change, \\ Nanjing University, Nanjing, China \\ HUITING MAO \\ Department of Chemistry, State University of New York College of Environmental Science and \\ Forestry, Syracuse, New York \\ CONGBIN FU \\ School of Atmospheric Sciences, and Institute for Climate and Global Change Research, and Jiangsu \\ Collaborative Innovation Center for Climate Change, Nanjing University, Nanjing, China
}

(Manuscript received 19 February 2018, in final form 16 November 2018)

\begin{abstract}
The western Pacific subtropical high (WPSH) is regarded as the key circulation system that dominates the summer heat waves over eastern China, but whether the WPSH-summer heat wave connection changes with time remains unknown. In this study, decadal variations in the WPSH-heat wave connection were examined for the period 1959-2016 using daily maximum temperature data from 654 observational stations across China and global reanalysis datasets. The results show that the correlation coefficient between the WPSH intensity (WPSHI) and the number of heat-wave days (NHD) was 0.65 ( $>99 \%$ confidence level) during positive phases of the Pacific decadal oscillation (PDO), whereas that during negative phases of the PDO was only 0.12 ( $<80 \%$ confidence level). The remarkable difference in correlations is due to the more westward extension of a stronger WPSH in El Niño decaying summers during the positive phases of PDO. The stronger Indian Ocean warming in El Niño decaying-year summers for PDO positive phases in comparison to PDO negative phases is associated with enhanced convection and heating, which further drive a stronger anticyclone over the northwestern Pacific, leading to a stronger and more westward-extending WPSH, which is favorable for more heat waves over eastern China.
\end{abstract}

\section{Introduction}

Extreme heat-wave events have drawn an increasing amount of attention in recent years due to their direct and disastrous impacts on human health and regional ecosystems (Luber and McGeehin 2008). For example, more than 25000 deaths could be attributed to the 2003 European heat waves (García-Herrera et al. 2010). In the monsoon regions of eastern China, where nearly 1000

Corresponding author: Prof. Congbin Fu, fcb@nju.edu.cn million people live, the rapidly increasing intensity of summer heat waves has been documented over the last few decades (Meehl and Tebaldi 2004; Ding et al. 2010) and projected for future scenarios in many studies (Sun et al. 2014; Ma et al. 2017; Li et al. 2018 a,b,c). Hence, it is of great importance to understand the variability and changes of summer heat waves in eastern China.

Previous studies on historical changes in heat waves over eastern China mainly focused on long-term trends and interannual variability. For instance, the rapid increase in the intensity of summer heat waves was attributed to 
global warming in several studies (Sun et al. 2014; Ma et al. 2017). In addition to anthropogenic influences, heat waves over eastern China also exhibit significant interannual variability. A climate modeling study suggested that approximately $2 / 3$ of the total variability in the July-August heat waves over the Yangtze River valley during 1979-2008 could be attributed to anomalous sea surface temperature (SST) forcing, while the remaining $1 / 3$ resulted from internal variability (Chen and Zhou 2018). It is suggested that the snow cover over the Qinghai-Tibetan Plateau (Wu et al. 2016), soil moisture over eastern China (Wang et al. 2018), local atmospheric anticyclonic circulation (Wang et al. 2016), and El Niño-Southern Oscillation (ENSO) (Arblaster and Alexander 2012) could modulate the interannual variation in heat waves over eastern China.

Among all the factors that affect heat waves over eastern China, the western Pacific subtropical high (WPSH) has been demonstrated to be the most direct circulation system. For instance, the 1994 heat wave over central China (Park and Schubert 1997) and the three hot summers in East China during 2003, 2006, and 2013 ( $\mathrm{Li}$ et al. 2015; Wang et al. 2016) were linked to anomalous activity of the WPSH. The WPSH may impact heat waves through two processes: 1) by directly causing a descending motion around its ridgeline (Kosaka et al. 2012) and 2) by impacting the northward propagation of the East Asian rain belt, which could modulate the spatial pattern of summer heat waves over China (Tao and Chen 1987; Ding et al. 2010). Although the WPSH has been widely used to understand the interannual variability of heat waves, less attention has been paid to the potential decadal variation of this kind of relationship. There is some evidence indicating that the interannual WPSH-heat wave relationship may not be stable. For example, the WPSH in the summer of 2010 was the strongest over the period 1948-2010, but the summer heat waves over eastern China were close to the climatological mean (CMA 2010). In the summer of 2013, the heat waves over east-central China were the strongest during 1948-2013 (CMA 2013), with recordbreaking daily maximum temperatures at 144 stations in the Yangtze River valley (Zhou et al. 2014), which was suggested to be a 270-yr extreme event (Sun et al. 2014). However, the WPSH in 2013 was not the strongest. A recent study suggested that it was not the intensity but the westward extension of the WPSH that played a key role in the occurrence of record-breaking summer heat waves in 2013 ( $\mathrm{Li}$ et al. 2015; Wang et al. 2016; CMA 2016). The underlying reasons for the unstable relationship between the interannual variations of the WPSH and heat waves remain unknown.

The WPSH is also an important component of the East Asian summer monsoon (EASM) circulation system
(Tao and Chen 1987; Ding and Chan 2005). Previous studies have demonstrated that the phase change of the Pacific decadal oscillation (PDO) is an important mechanism that dominates the interdecadal variability of the East Asian summer monsoon rainfall (Zhou et al. 2008, 2009b; Li et al. 2010; Qian and Zhou 2014). The PDO is a long-lived El Niño-like pattern of Pacific climate variability that generally persists for 20-30 years (Mantua et al. 1997). At the interannual time scale, the impact of El Niño on East Asian summer monsoon rainfall is most significant in the El Niño decaying-year summers due to the delayed forcing of tropical Indian Ocean warming [Yang et al. 2007; Xie et al. 2009; Wu et al. 2009; also see Li et al. (2017) for a review]. However, this kind of interannual relationship is unstable and shows decadal variations (Xie et al. 2010). The fluctuations in tropical sea surface temperature associated with the phase change of PDO are suggested to have the effect of modulating the interannual ENSO-EASM relationship (Feng et al. 2014; Song and Zhou 2015). All of these previous studies focused on the summer monsoon rainfall. Given that the WPSH is a component of the monsoon system, it is natural to hypothesize that the unstable interannual WPSH-heat wave relationship may be modulated by the PDO. To examine this hypothesis, this investigation aims to answer the following questions: 1) What are the features of the decadal changes in the interannual variability relationship between the WPSH and heat waves? 2) Is the PDO a factor that modulates the interannual WPSH-heat wave relationship? If so, what are the underlying mechanisms?

The remainder of the paper is organized as follows. The data and analysis method are described in section 2 . Section 3 presents the results. A summary along with a discussion is given in section 4 .

\section{Data and methodology}

\section{a. Observational data}

The daily maximum temperature and precipitation data used in this study were obtained from 824 surface stations from 1959 to 2016 in China. These datasets were quality controlled ( $\mathrm{Li}$ et al. 2004) and provided by the National Meteorological Information Center (NMIC) of the China Meteorological Administration (CMA) (http://data.cma.cn/). Stations were excluded when there were one or more days of missing data; as a result, 654 stations were selected to ensure data consistency over the study period.

Monthly mean sea surface temperature $\left(2^{\circ} \times 2^{\circ}\right)$ data for the same period were obtained from NOAA Extended Reconstructed Sea Surface Temperature data, 
version 3b (Smith et al. 2008). The SST dataset was employed to calculate the Niño-3.4 index. Following previous studies (Wang et al. 2008; Feng et al. 2014), El Niño decaying summers were defined using the detrended Niño-3.4 index as summers with preceding winters deviating from the climatological mean by $>0.7$ standard deviation. In addition, monthly interpolated outgoing longwave radiation (OLR) data from the National Oceanic and Atmospheric Administration (NOAA) were also used (Liebmann and Smith 1996). The data were available at a $2^{\circ} \times 2^{\circ}$ grid and covered the time period from June 1974 to 2016 except for a short period of MarchDecember 1978.

The Pacific decadal oscillation (PDO) index used in this study was provided by the Joint Institute for the Study of the Atmosphere and Ocean (JISAO; http://research.jisao. washington.edu/pdo/PDO.latest.txt) and the University of Washington. This index is defined as the time series of the first empirical orthogonal function of sea surface temperature over the North Pacific poleward of $20^{\circ} \mathrm{N}$. We note that the PDO broadened to cover the whole Pacific basin is known as the interdecadal Pacific oscillation (IPO) (Power et al. 1999; Folland et al. 2002). The PDO and IPO exhibit similar temporal evolution. To facilitate the discussion, we employ the term PDO in this study.

\section{b. Reanalysis data}

A reanalysis dataset of monthly mean horizontal wind $\left(2.5^{\circ} \times 2.5^{\circ}\right)$, vertical wind $\left(2.5^{\circ} \times 2.5^{\circ}\right)$, air temperature $\left(2.5^{\circ} \times 2.5^{\circ}\right)$, and geopotential height $\left(2.5^{\circ} \times 2.5^{\circ}\right)$ were obtained from the National Centers for Environmental Prediction (NCEP) and National Center for Atmospheric Research (NCAR) (Kalnay et al. 1996) for the period January 1959-December 2016.

\section{c. Western Pacific subtropical high intensity and the number of heat-wave days}

The geopotential heights at mid- and low-tropospheric levels have traditionally been used to measure the WPSH in both operational service and research. However, recent studies have suggested that the streamfunction is recommended to avoid the impact of global warming on the definition of the WPSH index based on the geopotential height (Li et al. 2012; Wu et al. 2016; He et al. 2015). Hence, following Li et al. (2012), the streamfunction in the lower troposphere $(700 \mathrm{hPa})$ averaged from June to $\mathrm{Au}$ gust and based on the horizontal wind field was used to define the WPSHI in this study.

The number of heat-wave days (NHD) index was calculated using the daily maximum temperature. The NHD was defined as the number of days where the daily maximum temperature exceeded $35^{\circ} \mathrm{C}$, which was recommended by the NMIC of the CMA (www.cma.
gov.cn/en/WeatherWarnings/) and has been widely used in both operational service and previous research (Sun et al. 2014; Wang et al. 2018). In addition, we derived the normalized WPSHI and NHD via transforming their interannual variation into a new series with a mean of 0 and a standard deviation of 1 .

\section{d. Ensemble empirical mode decomposition}

To extract the interannual variation components in the time series for the NHD and WPSHI, a data-adaptive filter, the ensemble empirical mode decomposition (EEMD), was employed (Huang and Wu 2008; Wu and Huang 2009). The EEMD was developed based on empirical mode decomposition (EMD) (Huang et al. 1998), which is suitable for one-dimensional nonlinear and nonstationary data due to its high locality and adaptiveness. The EEMD improves the robustness of EMD decomposition when data are perturbed with noise, guaranteeing that the decomposition is not sensitive to the noise. Thus, the EEMD method is suitable for analyzing meteorological data, which are usually nonstationary and nonlinear and contain noise. Traditional Fourier spectrum-based filtering requires a predesign filtering window, which may cause numerous spikes at its harmonics; thus, the derived signal in a specific time scale may lose energy (Huang et al. 1998). The EEMD filter is able to avoid the energy loss caused by spikes at its harmonics. In our analysis, we used the EEMD as a one-dimensional filter to filter out the secular trend and low-frequency oscillations in the time series of the WPSHI, NHD, and Niño-3.4 index. Similar filtering was performed on the SST and wind fields (individual grid points) and geopotential height field (domain averaged over $0^{\circ}-45^{\circ} \mathrm{N}$, $\left.180^{\circ} \mathrm{E}-180^{\circ} \mathrm{W}\right)$. The EEMD was also used to filter out the high-frequency components of the PDO with a wave period shorter than 10 years.

\section{e. Composite analysis}

In our analysis, eight El Niño decaying years during a positive phase of the PDO (1978, 1983, 1987, 1988, 1992, 1998, 2003, and 2016) and seven El Niño decaying years during a negative phase of the PDO (1964, 1966, 1969, 1973, 1977, 2007, and 2010) were selected for the period 1959-2016. These El Niño decaying years were employed for composite analysis, using the same climatology for 1959-2016 for both the positive and negative phases of the PDO. In addition, the Student's $t$ test was used to examine the statistical significance of the composite analysis and linear regression coefficients.

\section{Results}

The climatological mean and standard deviation of the NHD in the summer [the June-August (JJA) average] 
(a) Mean NHD (Number of days)

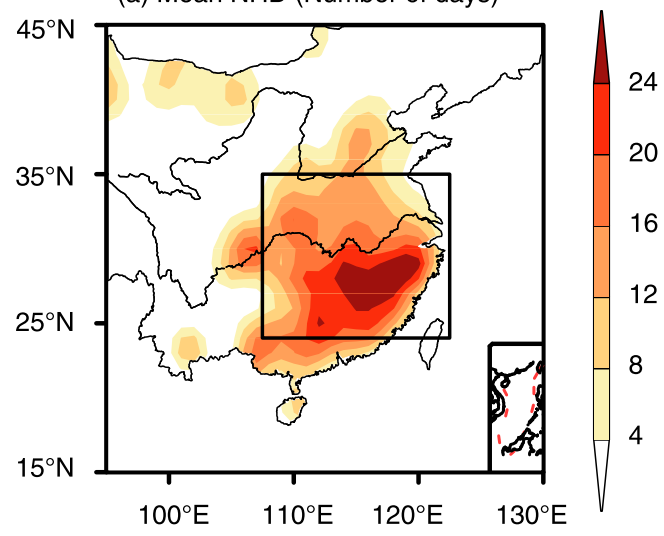

(b) STD NHD (Number of days)

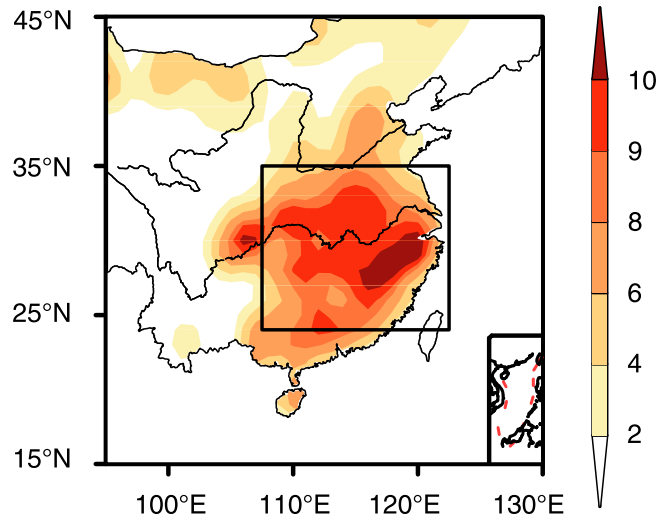

(c) Raw NHD (Number of days)

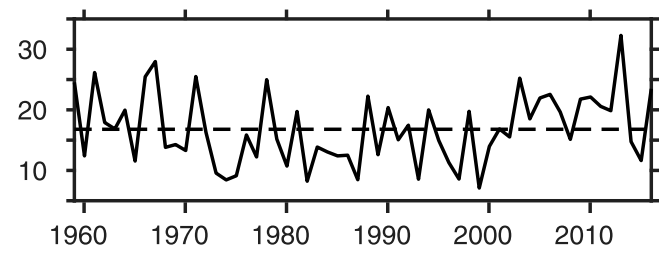

(d) NHD EEMD components

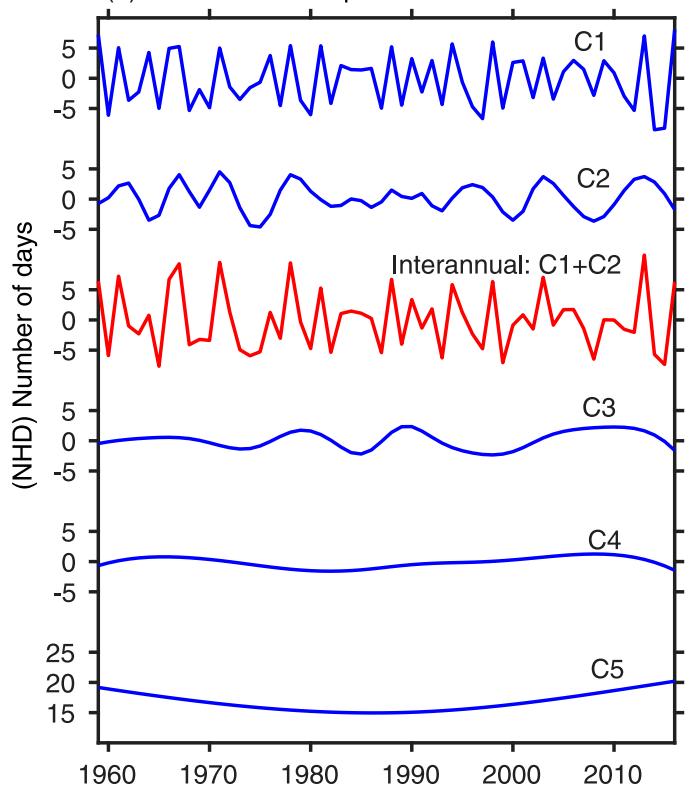

FIG. 1. Distributions of (a) climatological-mean values and (b) standard deviations of the number of heat-wave days (NHD) in the summertime over China during 1959-2016 (days). The black rectangle $\left(24^{\circ}-35^{\circ} \mathrm{N}, 107.5^{\circ}-\right.$ $122.5^{\circ} \mathrm{E}$ ) highlights the maximum standard deviation and mean values of the NHD. (c) The raw time series of the summertime NHD averaged over the black rectangle shown in (a). (d) The different components (blue line) of the NHD derived by the EEMD method and the interannual variability component (red line) of the NHD. The interannual variability is the sum of $\mathrm{C} 1$ and $\mathrm{C} 2$. The $y$ axis of $(\mathrm{d})$ is the number of heat-wave days.

at 654 monitoring stations for the study period (19592016) are shown in Fig. 1. Climatologically, a large NHD center was located over eastern China (Fig. 1a), where the climatological mean of the NHD exceeded 24 days, which was a period shorter than the 3 months of the summer season but undoubtedly important due to its large social and economic impacts. The large NHD standard deviation center coincided with that of the climate mean (Fig. 1b). The maximum standard deviation along the Yangtze River valley was greater than 10 days. This maximum NHD center was closely associated with the WPSH (Wang et al. 2018). To quantify the interannual variation in the NHD, a regional average NHD was used over the domain $24^{\circ}-35^{\circ} \mathrm{N}, 107.5^{\circ}-122.5^{\circ} \mathrm{E}$ over eastern China (Fig. 1a), which is also a region with a dense population. The domain-averaged NHD ranged from 7 to 32 days, indicating great interannual variability (Fig. 1c). Figure 1d shows the results of the EEMD decomposition. The annual data over 58 years (19592016) were decomposed into five components. The components $\mathrm{C} 1$ and $\mathrm{C} 2$ represent the variability of interannual scales, and the components $\mathrm{C} 3-\mathrm{C} 5$ represent the variability from decadal to multidecadal scales. In our following analysis, we used the sum of $\mathrm{C} 1$ and $\mathrm{C} 2$ to represent the interannual variability of the NHD index. We note that the interannual NHD index time series derived from the EEMD method was highly correlated with that derived from the normal Lanczos filter (Duchon 1979) at time windows shorter than 10 years, and the correlation coefficient was 0.97 over the period of 1959-2016.

The WPSHI climatological mean was calculated using the 700-hPa streamfunction (Fig. 2a). The zero-value contour outlined the spatial coverage of the WPSH. The WPSH climatological mean extended westward, approaching the coast of southeastern China. To examine the relationship between the WPSHI and NHD, the 
(a)

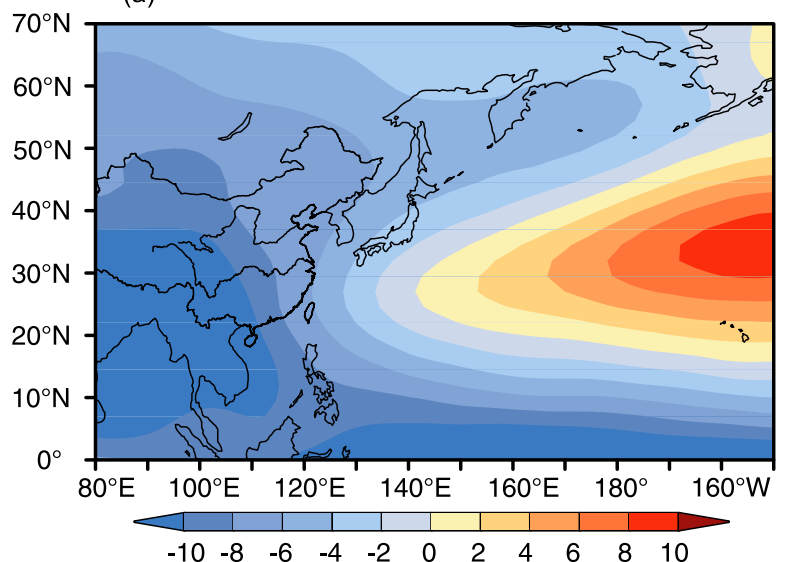

(b)

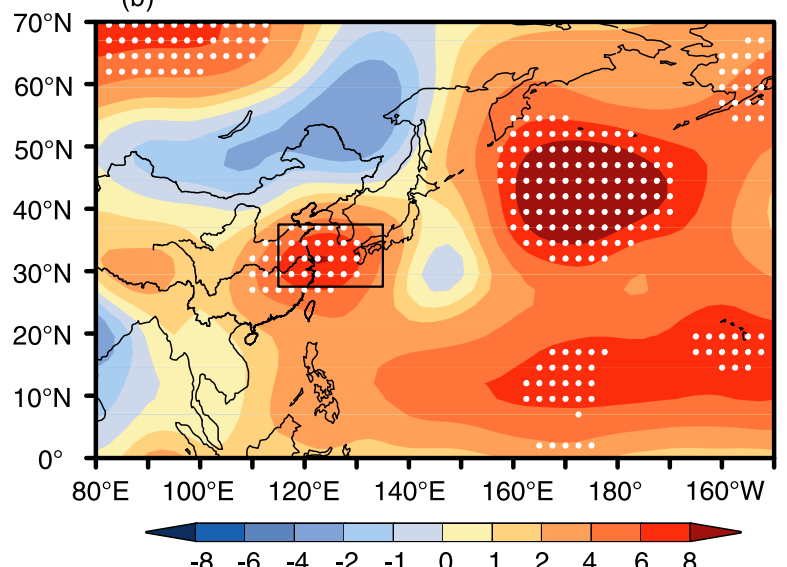

(c)

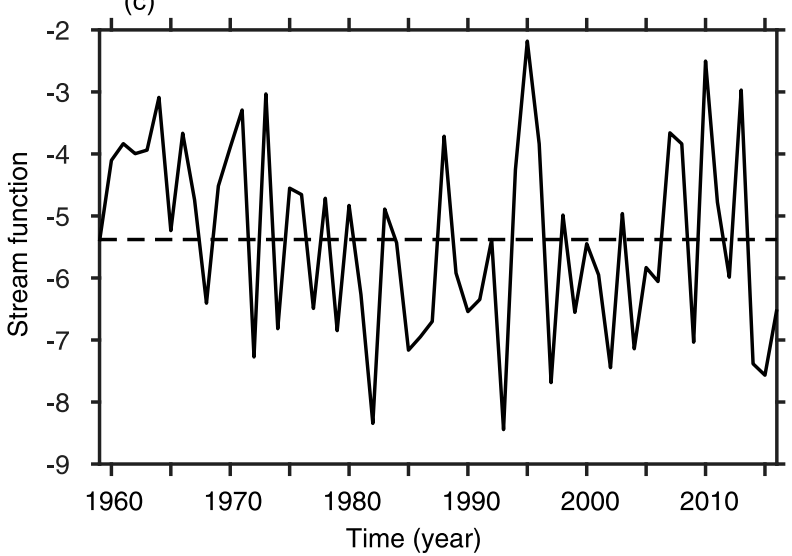

FIG. 2. Distributions of (a) the JJA climatological-mean 700-hPa streamfunction $\left(1 \times 10^{6} \mathrm{~m}^{2} \mathrm{~s}^{-2}\right)$ and $(\mathrm{b})$ the anomalies of the $700-\mathrm{hPa}$ streamfunction $\left(1 \times 10^{5} \mathrm{~m}^{2} \mathrm{~s}^{-2}\right)$ regressed upon the interannual variability of NHD index during 1959-2016. Anomalies statistically significant at the $5 \%$ level are marked with white dots. The black rectangle $\left(25^{\circ}-35^{\circ} \mathrm{N}, 110^{\circ}-130^{\circ} \mathrm{E}\right)$ highlights the region where the NHD-related WPSHI index was defined. (c) The raw time series of the 700-hPa streamfunction averaged over the black rectangle $\left(1 \times 10^{6} \mathrm{~m}^{2} \mathrm{~s}^{-2}\right)$.
700-hPa streamfunction anomalies were regressed with respect to the NHD. The regressed streamfunction resulted in an approximate positive uniformity over the domain (Fig. 2b). The maximum 700-hPa streamfunction anomalies were located over eastern China $\left(25^{\circ}-35^{\circ} \mathrm{N}\right.$, $\left.110^{\circ}-130^{\circ} \mathrm{E}\right)$ and the North Pacific Ocean $\left(30^{\circ}-55^{\circ} \mathrm{N}\right.$, $\left.150^{\circ} \mathrm{E}-160^{\circ} \mathrm{W}\right)$. We defined the $700-\mathrm{hPa}$ streamfunction averaged over eastern China (see the black rectangle marked in Fig. 2b) as the WPSH index (hereafter WPSHI). As shown in Fig. 2c, the time series of WPSHI showed robust interannual variations.

Previous studies have demonstrated that the impact of the ENSO on the WPSH is most significant during the summer of an El Niño decaying year based on Indian Ocean basin warming, which produces an anticyclone over the western Pacific as a Kelvin response to warm anomalies (Wang et al. 2000; Lau and Nath 2003; Lau and Wang 2006; Yang et al. 2007; Xie et al. 2009; Wu et al. 2009; Song and Zhou 2014; Li et al. 2017). To reveal the link between the heat waves and ENSO forcing through the WPSH, in Fig. 3, we compare the summertime $850-\mathrm{hPa}$ horizontal wind anomalies regressed upon the time series of the WPSH index, NHD index, and preceding winter [December-February (DJF)] Niño-3.4 index separately. As expected, an anomalous anticyclone was evident over the western Pacific and extended to the eastern Asian continent in the El Niño decayingyear summers (Fig. 3c). The pattern of wind anomalies associated with the WPSH index closely resembled that associated with El Niño (cf. Figs. 3a and 3c). At the regional scale, the 850-hPa wind anomalies overlaying the heat waves were a continental lobe of the wind responses associated with the WPSH (cf. Figs. 3a and 3b). The spatial similarity of circulation responses strongly indicates that the interannual variation of the heat waves over southeastern China was driven by tropical ENSO events through changes in the WPSH. This relationship was further confirmed by the coherent variations of the time series (shown below in Fig. 4a), where the normalized WPSH index was higher than 0 in 12 out of the total 15 El Niño decaying-year summers.

To illustrate the coherent variations between the WPSH and the NHD, Fig. 4a shows the normalized interannual time series for the NHD index and WPSH index. The interdecadal components and nonlinear trends were removed using the EEMD method. While a strong connection was seen between the two indices, the relationship was unstable and showed decadal variations. Specifically, the WPSHI was highly correlated with the NHD index in the 1980s, 1990s, and 2010s, but the decades of the 1970s and 2000s saw low and statistically insignificant correlations. The correlation coefficients for the 1970s and 2000s were only 0.07 and 0.13 , respectively. 
(a) WPSHI

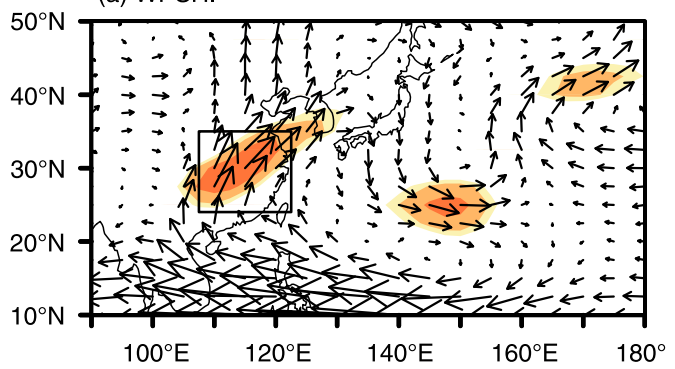

(b) NHD index

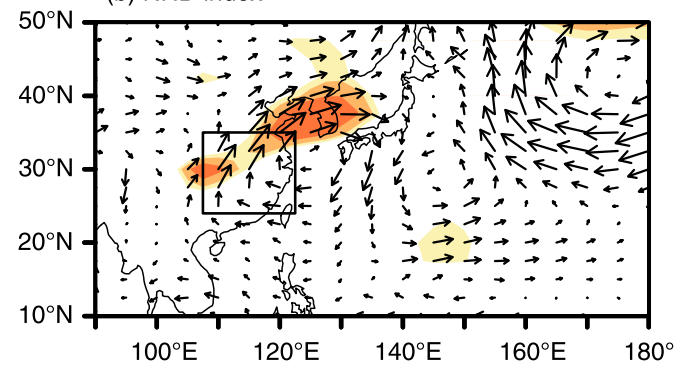

(c) Niño3.4 index

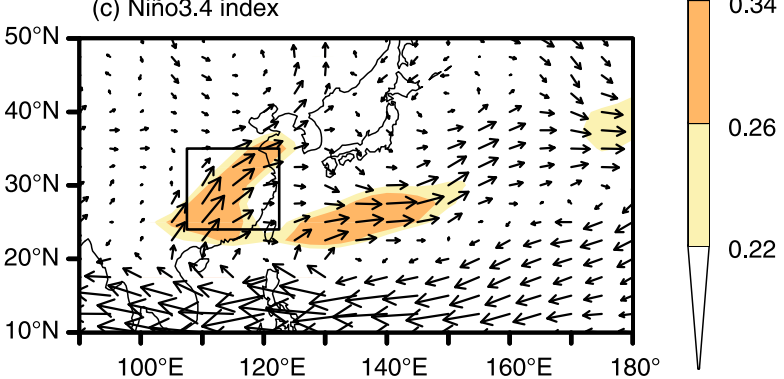

FIG. 3. The JJA-mean 850 -hPa horizontal wind anomalies regressed upon the time series of (a) the WPSHI, (b) the NHD index, and (c) the preceding DJF Niño-3.4 index over the period of 19592016. Zonal wind anomalies statistically significant at the $10 \%, 5 \%$, and $1 \%$ level are shaded with a light, medium, and dark orange color, respectively.

The interannual connection between the East Asian climate and ENSO can be modulated by the PDO (Feng et al. 2014; Song and Zhou 2015). To understand the potential modulating effect of the PDO on the interannual WPSHI-NHD relationship, the positive and negative phases of the PDO are marked in Fig. 4a. Note that the positive and negative phases of the PDO index were defined based on the filtered index shown in Fig. 4b. Clearly, the decades during the positive phase of the PDO saw significant correlations between the WPSHI and NHD index, whereas those decades during the negative phases of the PDO exhibited poor correlations. The WPSHI-NHD correlation coefficient during a positive phase of the PDO was 0.65 ( $>99 \%$ confidence level) but only 0.12 during a negative phase of PDO, which was not statistically significant at the $5 \%$ level.

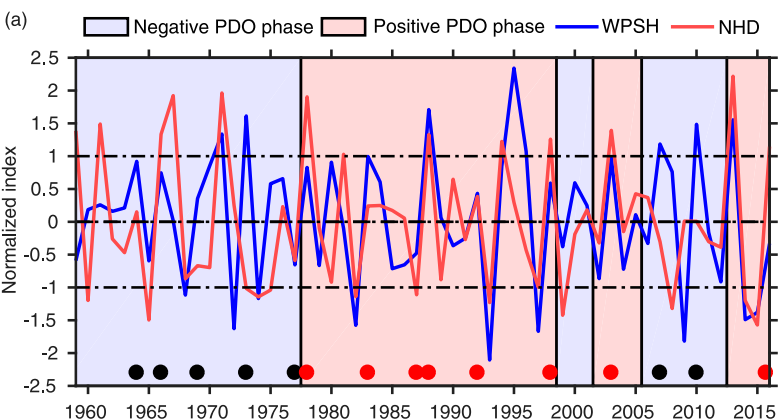

(b)

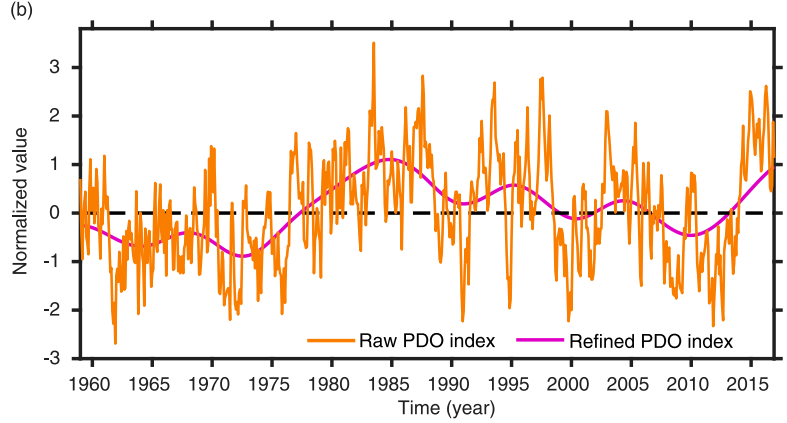

FIG. 4. (a) Normalized WPSH and NHD indices on interannual scales. The solid blue line represents the WPSH index, and the solid red line represents the NHD index. The positive and negative phases of the PDO are represented by light red and light blue shading, respectively. The red dots and black dots represent El Niño decaying summers during the positive and negative phases of the PDO, respectively. (b) The raw monthly PDO index (orange) and the refined PDO index (purple). The refined PDO was derived by filtering out the components with a wave period shorter than 10 years.

To further understand how the WPSHI-NHD relationship changed during the different phases of the PDO, anomalies were calculated for the NHD, daily maximum temperature, and precipitation for El Niño decaying-year summers during the two phases of the PDO (Fig. 5). The anomalies were calculated relative to the 58-yr-mean climatology. There were remarkable differences in the positions of the maximum positive NHD anomalies between the two phases of the PDO. During the positive phases of the PDO, a large area of positive NHD anomalies was observed over the southern Yangtze River during an El Niño decaying summer (Fig. 5a). The maximum NHD anomaly was greater than 5 days ( $>90 \%$ confidence level). In comparison, a much smaller area situated between the Yangtze and Yellow Rivers with positive NHD anomalies was found during the negative phases of the PDO (Fig. 5b).

During El Niño decaying summers, enhanced precipitation is observed along the Yangtze River valley due to the anomalous western Pacific anticyclone driven by the Indian Ocean warming (Wang et al. 2001; Kosaka et al. 2013; Li et al. 2017). This kind of ENSO-EASM 
(a) NHD_PDO(+)

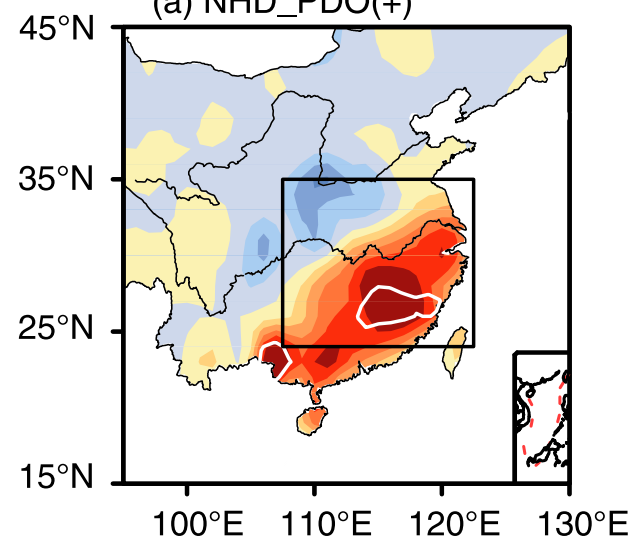

(b) NHD_PDO(-)

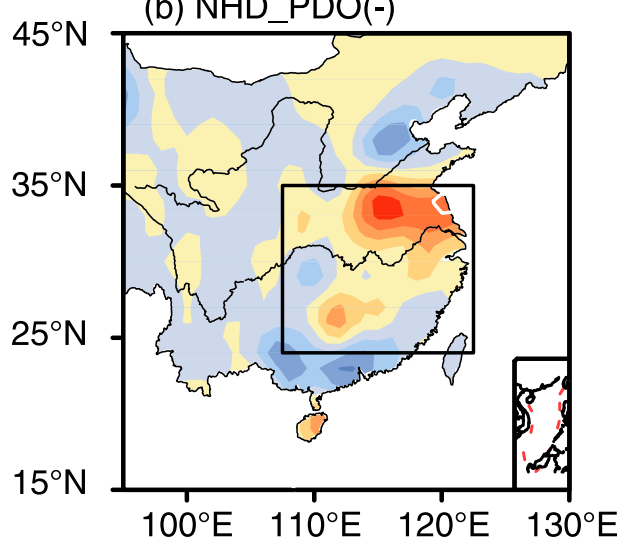

\begin{tabular}{llllllllll|l|l|l|}
\hline & & & & & & & & & & & \\
\hline
\end{tabular}

(c) Tmax_PDO(+)

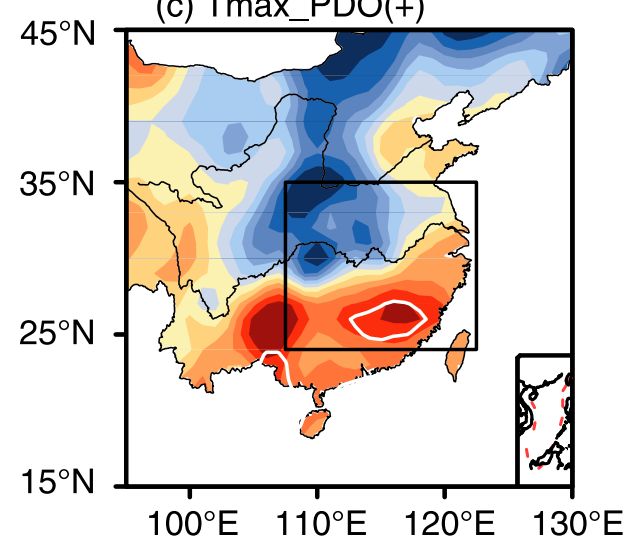

(d) Tmax_PDO(-)
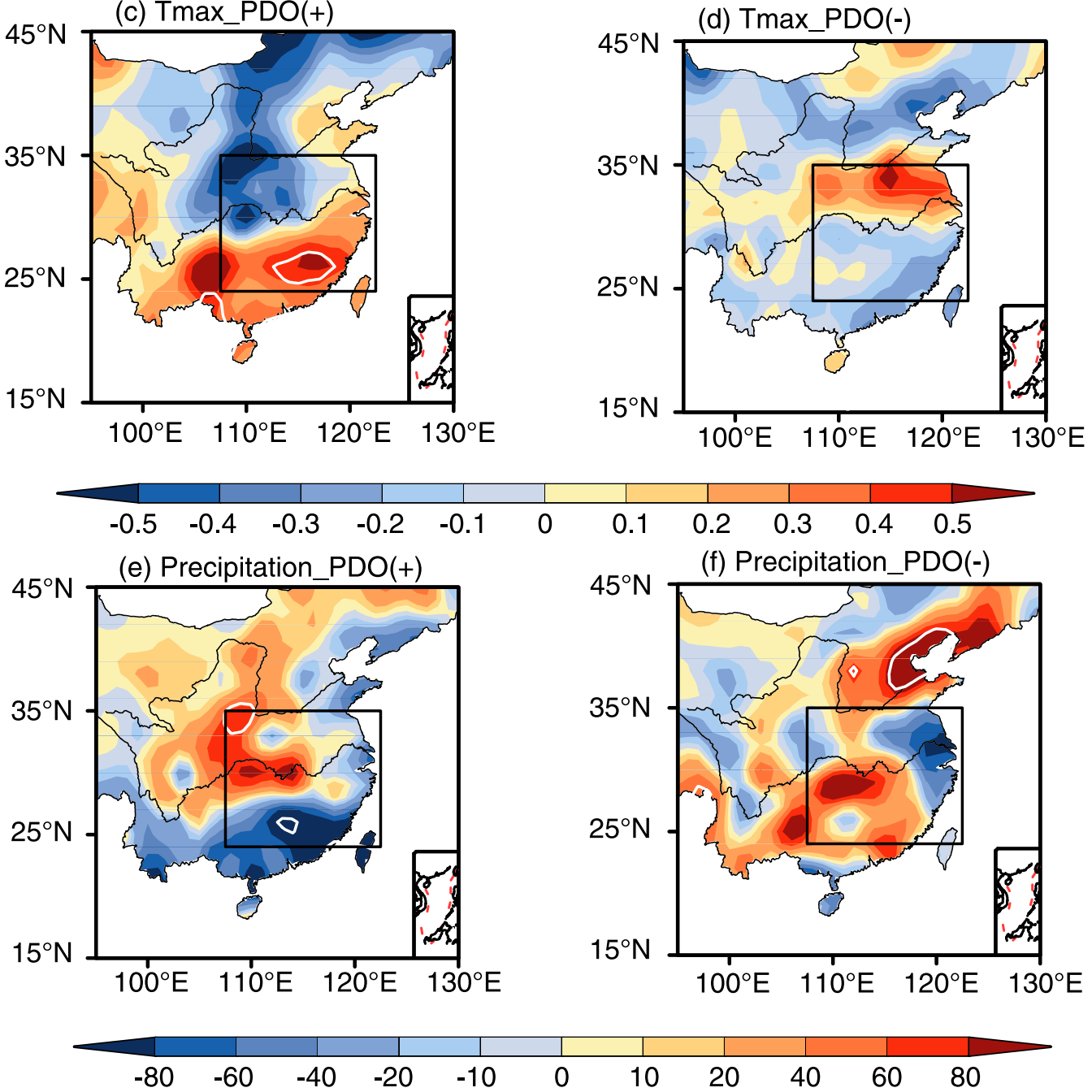

FIG. 5. JJA anomalies of the (a),(b) NHD (days), (c),(d) daily maximum temperature $\left({ }^{\circ} \mathrm{C}\right)$, and (e),(f) precipitation $(\mathrm{mm})$ over eastern China in El Niño decaying summers during positive and negative phases of PDO, denoted as $\mathrm{PDO}(+)$ and $\mathrm{PDO}(-)$, respectively. The white lines indicate where the anomalies are statistically significant at the $10 \%$ level. 
relationship is stable during positive phases of the PDO. To reveal the possible impacts of enhanced precipitation on the NHD, the daily maximum temperature and precipitation for El Niño decaying summers during the two phases of PDO are exhibited in Figs. 5c-f. In positive phases of the PDO, the temperature and precipitation anomalies were characterized by a dipole structure over the target area. Heavier precipitation associated with a lower temperature was noted along the Yangtze River valley. However, no evident relationship was observed between the anomaly centers of the NHD and precipitation. How do we explain the mismatch between the precipitation and NHD changes? This resulted from the seasonal meridional evolution of the monsoon rainband. One prominent feature of the EASM is the precipitation concentration in an east-west-elongated rain belt, which affects China, Japan, the Korean peninsula, and the surrounding seas. The position of this monsoon rainband is not stationary during the entire summer season. The monsoon rainband extends from the Indochina Peninsula and the South China Sea from the Philippines to the Yangtze River valley in early to mid-June, and the mei-yu (also called baiu in Japanese and changma in Korean) begins. The monsoon penetrates northern China in mid-July (see Fig. 2 of Zhou et al. 2009b). Thus, the rainy season along the Yangtze River valley generally lasts from 15 June to 15 July, the so-called mei-yu period in China. The total period of rainy days lasts less than 3 months of the summer season, but the amount of JJA rainfall along the Yangtze River valley is dominated by the contribution of the mei-yu period. The enhanced precipitation along the Yangtze River valley in El Niño decaying summer generally occurs during this rainy period (15 June- 15 July). This scenario is confirmed by Fig. 6, where we compare the monthly evolution of the NHD and precipitation anomalies from June to August. It is evident that excessive precipitation along the Yangtze River valley occurred mainly in June and July, whereas the NHD events were mainly south of the Yangtze River valley in July and August. Because our analysis on the NHD focused on the whole boreal summer season that covers June, July, and August, which is longer than the actual rainy period, the anomalies of NHD did not strictly follow the "more precipitationless NHD" relationship. Visual inspections of the anomalies for the individual months of July and August do show a "less precipitation-more heat waves" relationship in the regions south of the Yangtze River valley (cf. Fig. 6c with Fig. 6d, and Fig. 6e with Fig. 6f).

The above analyses show that the interannual connection between the NHD and ENSO through the WPSH is modulated by the phase changes of the PDO. To reveal how the PDO modulates the WPSH, in Fig. 7 we compare the patterns of the WPSH in El Niño decaying-year summers during the positive and negative phases of the PDO. Both the El Niño decaying summers in the positive and negative phases of the PDO resulted in prevailing positive anomalies over the western portion of the WPSH, indicating an enhancement of the WPSH. However, there were several spatial differences in the location and intensity of the WPSH between the two phases of the PDO. During the positive phases of the PDO, the enhancement of the WPSH was stronger and much more significant west of $120^{\circ} \mathrm{E}$ compared to that east of $120^{\circ} \mathrm{E}$, suggesting a remarkable westward extension of the WPSH. Positive WPSH anomalies ( $>95 \%$ confidence level) extended from the Philippines and the South China Sea toward a majority of eastern China (Fig. 7a). The intensified WPSH corresponded well with the locations of the largest NHD anomalies (Fig. 5a). In comparison, the WPSH during the negative phases of the PDO remained stationary (Fig. 7b), with the WPSH mainly enhanced east of $120^{\circ} \mathrm{E}$. There were two centers in the anomaly field: one was located in the tropics, extending from the northwestern Pacific to the South China Sea, and the other was located in the subtropics, extending from northern Japan to northern China. The northern center coincided well with the anomalies of NHD over the regions between the Yangtze River and the Yellow River.

The difference in the position of the WPSH between the positive and negative phases of the PDO could be identified from the contours of the geopotential height of $5860 \mathrm{gpm}$, which is a useful measure of the edge of the WPSH (Figs. 7c,d). The westward extension of WPSH was confirmed in Figs. $7 \mathrm{c}$ and $7 \mathrm{~d}$. Compared to the negative phases of the PDO, the western edge of the summertime WPSH shifted westward by $5^{\circ}$ in the positive phases of the PDO. Subseasonal characteristics in the position of the WPSH were also evident. In the positive phases of the PDO, a large area of eastern China was dominated by a persistent intensified WPSH in July and August, corresponding well with the locations of the largest NHD anomalies. The subseasonal variations of the WPSH also explain the changes in the precipitation and NHD anomalies shown in Fig. 6. In comparison, the evolution of the WPSH during the negative phases of the PDO was characterized by a northward and eastward shrinking from June to July; hence, the western edge of the WPSH barely reached the coast of southeastern China during July and August, leading to a weak relation between the heat waves over eastern China and the WPSH.

Why are there different responses of the WPSH in El Niño decaying-year summers during positive and negative phases of the PDO? In Fig. 8, we examine the 
(a) NHD June PDO(+)

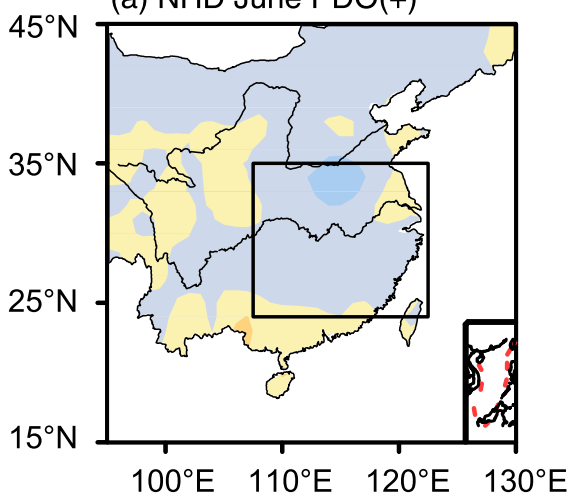

(c) NHD July PDO(+)

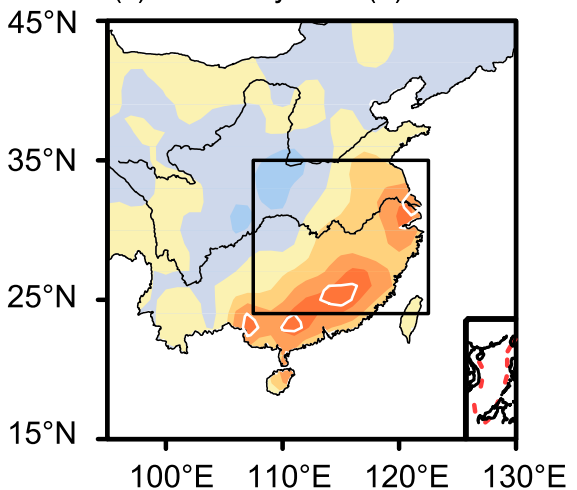

(e) NHD August PDO(+)

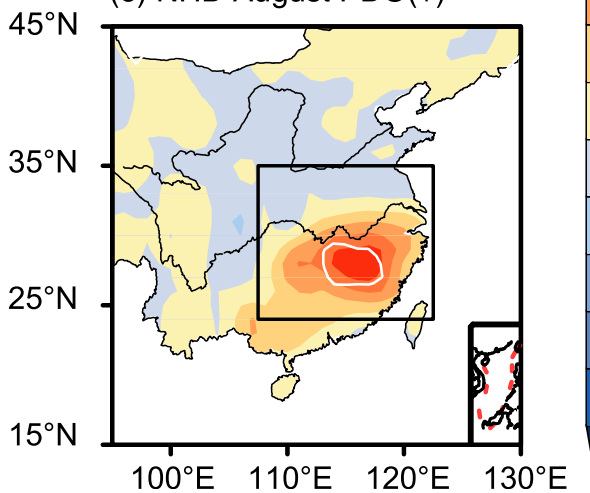

(b) Precip. June PDO(+)

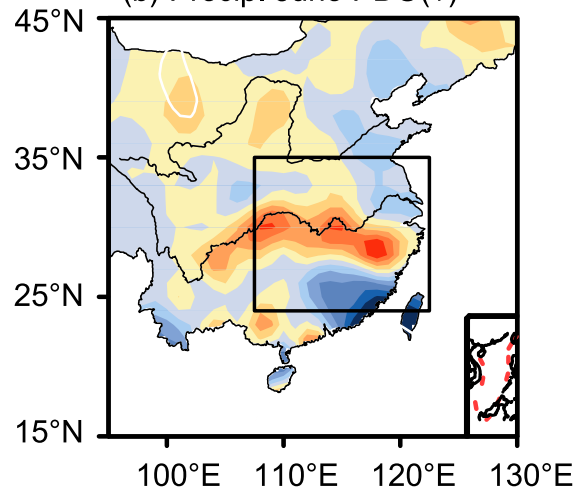

(d) Precip. July PDO(+)

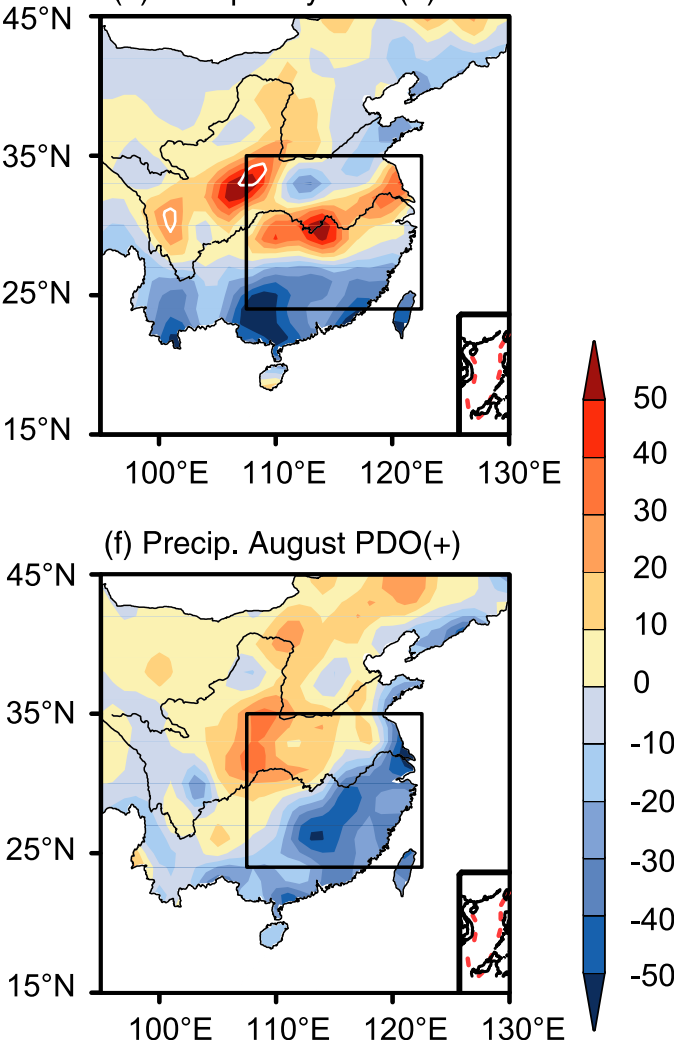

FIG. 6. Monthly anomalies of (a),(c),(e) NHD (days) and (b),(d),(f) precipitation (mm) in an El Niño decaying year for (a),(b) June, (c),(d) July, and (e),(f) August during positive phases of the PDO. The white lines indicate where the anomalies are statistically significant at the $10 \%$ level.

difference in the SST anomalies in El Niño decayingyear summers associated with positive and negative phases of the PDO. Both Figs. 8a and $8 \mathrm{~b}$ feature an Indian Ocean warming due to the capacitor effect of remote El Niño forcing (Xie et al. 2009), but the anomalies for the PDO positive phase were stronger than those for the negative phase, especially in the eastern part of the Indian Ocean (see the difference field in Fig. 8c). Previous studies have demonstrated that the anomalous heating associated with the warmer Indian Ocean SST drives anomalous easterlies as a Kelvin wave response to the east of the heat source. The Kelvin wave easterlies have a maximum at the equator and decrease with latitudes, generating the anticyclonic shear over the northwestern Pacific [Xie et al. 2009; Wu et al. 2009; also see $\mathrm{Li}$ et al. (2017) for a review]. The anomalous anticyclone ultimately leads to position changes of the WPSH that affect the heat waves over eastern China. 
(a) PDO (+)

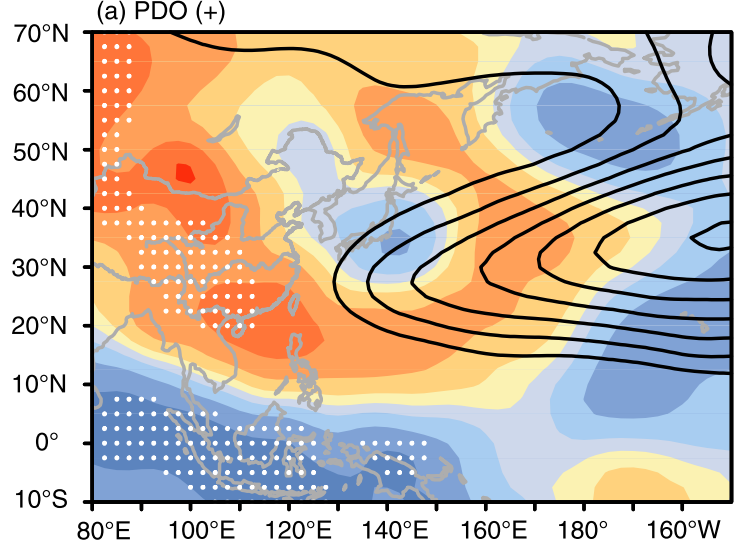

(b) PDO (-)

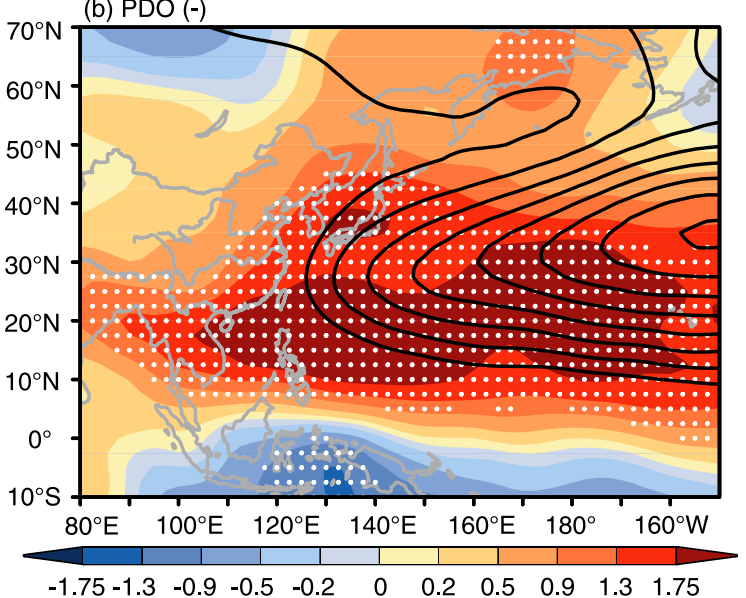

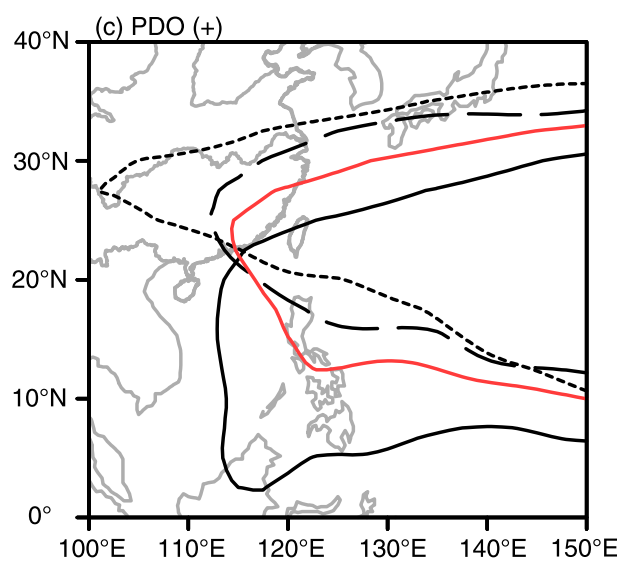

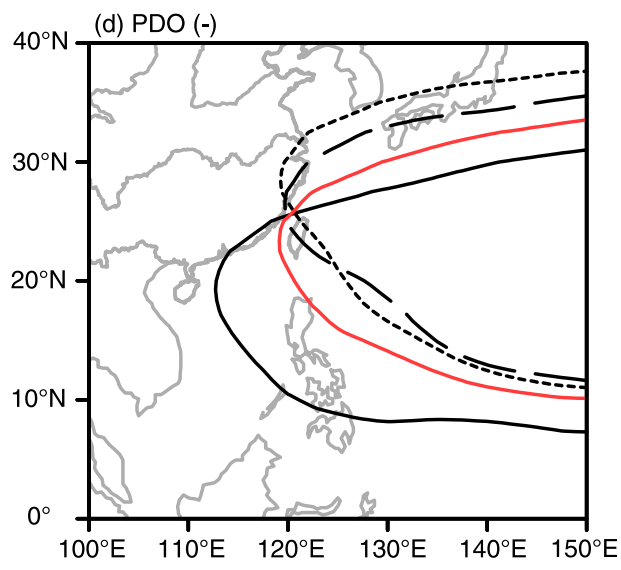

FIG. 7. Composite 700-hPa streamfunction anomalies $\left(1 \times 10^{6} \mathrm{~m}^{2} \mathrm{~s}^{-2}\right.$; shaded $)$ during El Niño decaying summers for (a) positive and (b) negative phases of the PDO. Anomalies statistically significant at the $5 \%$ level are marked with white dots. The summertime climatological-mean $700-\mathrm{hPa}$ streamfunction is shown as a solid black line in (a) and (b). The outermost line equals $-4 \times 10^{6} \mathrm{~m}^{2} \mathrm{~s}^{-2}$, with intervals of $2 \times 10^{6} \mathrm{~m}^{2} \mathrm{~s}^{-2}$. (c), (d) The locations of the WPSH (marked by a 5860-gpm contour of a composite of the 500-hPa detrended geopotential height superimposed on the 1986-2015 climatological mean) in El Niño decaying-year summers during the positive and negative phases of the PDO, respectively. The red solid lines are for the JJA-mean condition, while the black solid lines, black dashed lines, and black dotted lines are for the conditions in June, July, and August, respectively.

The driving of Indian Ocean warming to the westward extension of the WPSH has been demonstrated by numerical model experiments ( $\mathrm{Li}$ et al. 2008; Zhou et al. 2009a). In Figs. 8a and 8b, we see clear northwestern Pacific anticyclones in both the positive and negative phases of the PDO. During the positive phases of the PDO, the Indian Ocean warming in El Niño decayingyear summers due to the capacitor effect (Xie et al. 2009) is stronger than that during the negative phases of the PDO (Fig. 8c). For example, the tropical and eastern Indian Ocean SST anomaly was approximately $0.3^{\circ}-$ $0.5^{\circ} \mathrm{C}$ warmer; thus, the stronger heating associated with the enhanced convection over the Indian Ocean, as evidenced by the outgoing longwave radiation changes shown in Fig. 8c, drove a stronger and more westward anomalous anticyclone over the northwestern Pacific through the Kelvin wave response.

The stronger forcing of Indian Ocean warmer SST anomalies during the positive phases of the PDO was also demonstrated by the responses of the troposphericmean temperature, a conventional way for measuring the free atmosphere's response to tropical ocean warming (Santer et al. 2005; Trenberth et al. 2005; Trenberth and Smith 2006; Zhou and Zhang 2011). In Fig. 9, we show the tropospheric-mean $(200-500 \mathrm{hPa})$ temperature anomalies in El Niño decaying-year summers during the positive and negative phases of the PDO. In response to the anomalous heating associated with the Indian Ocean SST warming, tropospheric warming was observed over the Indian Ocean, with two off-equatorial 

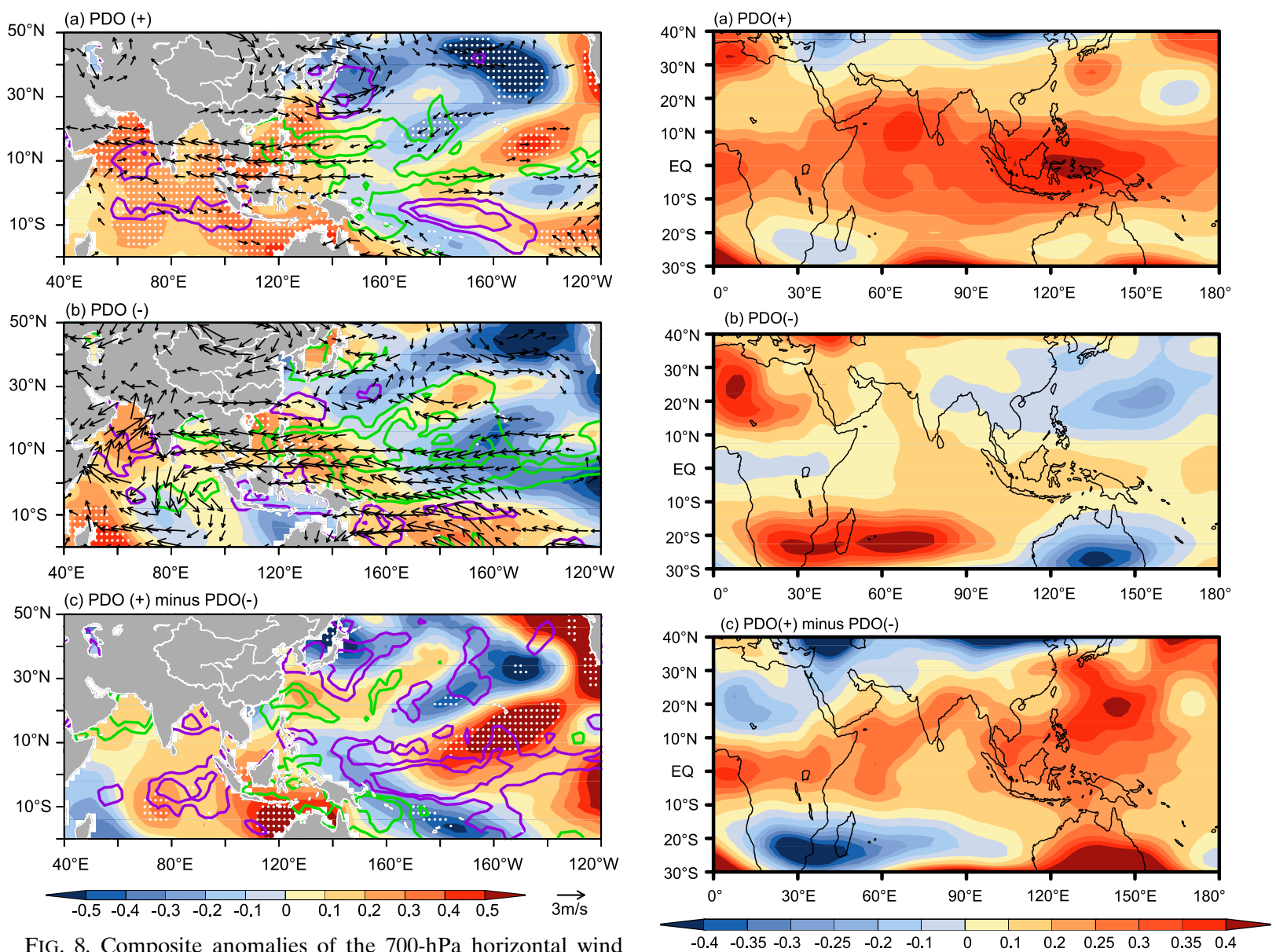

FIG. 8. Composite anomalies of the $700-\mathrm{hPa}$ horizontal wind (vectors; $\mathrm{ms}^{-1}$ ), sea surface temperature (shaded; ${ }^{\circ} \mathrm{C}$ ), and outgoing longwave radiation (OLR; contours; $\mathrm{W} \mathrm{m}^{-2}$ ) in El Niño decaying-year summers during (a) positive and (b) negative phases of the PDO. (c) The difference in the SST (shaded; ${ }^{\circ} \mathrm{C}$ ) and OLR (contours; $\mathrm{W} \mathrm{m}^{-2}$ ) during $\mathrm{El}$ Niño decaying summers between positive and negative phases of the PDO. SST anomalies statistically significant at the $5 \%$ level are marked with white dots. Only horizontal winds exceeding $0.6 \mathrm{~m} \mathrm{~s}^{-1}$ are drawn. The purple lines and green lines represent negative (indicating enhanced convection and heating) and positive (indicating suppressed convection and heating) values, respectively, with intervals of $5 \mathrm{~W} \mathrm{~m}^{-2}$. The composite anomalies are for the period of 1974-2016 due to the availability of OLR data.

maximal centers located on both sides of the equator over the Indian Ocean and an equatorial warming wedge to the east, resembling a typical Matsuno-Gill type response pattern (Matsuno 1966; Gill 1980). The prominent features of the tropospheric temperature anomalies associated with the positive PDO in comparison to the negative phases of the PDO were the stronger off-equatorial Rossby wave maxima and the stronger equatorial Kelvin wave maximum (Fig. 9c), again demonstrating the stronger Indian Ocean SST forcing during the positive phase of the PDO.

FIG. 9. Composite anomalies of the tropospheric-mean (200$500 \mathrm{hPa}$ ) temperature in El Niño decaying-year summers during (a) positive and (b) negative phases of the PDO $\left({ }^{\circ} \mathrm{C}\right)$. (c) The difference between (a) and (b).

\section{Summary and concluding remarks}

The western Pacific subtropical high (WPSH) is an important circulation system that affects the interannual variation of the summer heat waves over eastern China. In this study, we present observational evidence that the interannual WPSH-heat wave relationship is unstable and exhibits decadal variations over the period of 19592016. Analysis reveals that the interannual WPSH-heat wave variability is modulated by the phase changes of the PDO. The underlying mechanisms are depicted in Fig. 10. The major findings are summarized below.

The interannual relationship between the WPSHI and the number of heat-wave days (NHD) shows decadal variations over the period of 1959-2016. This kind of variable interannual connection is modulated by the phase changes of the PDO. During the positive PDO phases, the WPSHI and the NHD were correlated at $r=0.65$ (statistically significant at the $1 \%$ level), but the 


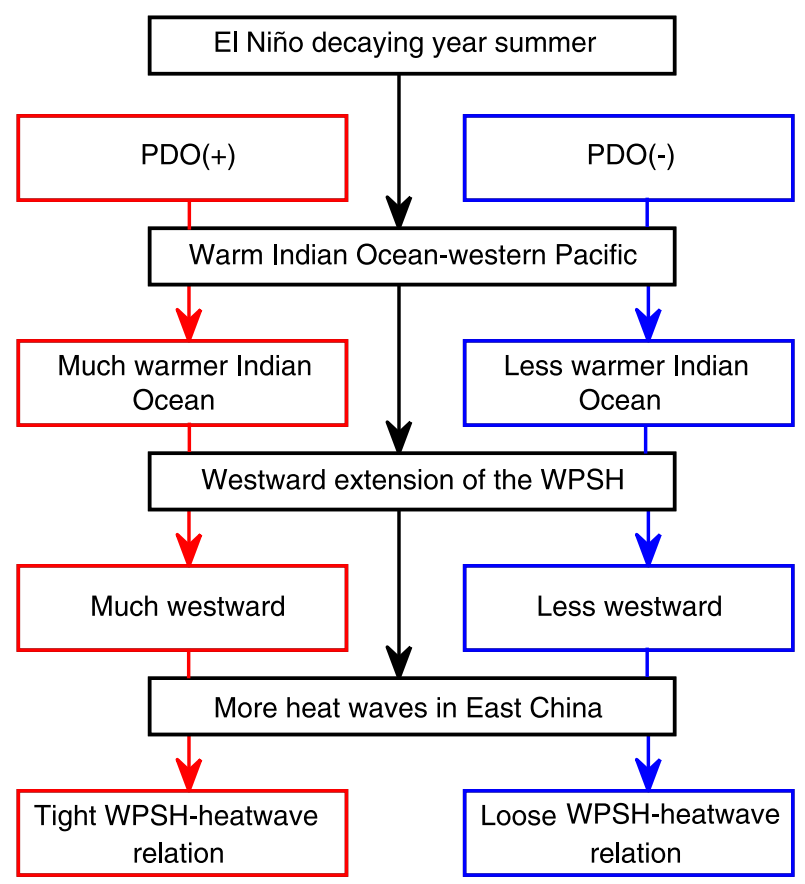

FIG. 10. Flowchart depicting how different PDO phases modulate the effects of decaying El Niño on a summertime heat wave in eastern China through the western Pacific subtropical high.

correlation coefficient decreased to $r=0.12$ (statistically insignificant at the $5 \%$ level) during the negative PDO phases.

The interannual variability of the WPSH is driven by the Indian Ocean SST warming in El Niño decayingyear summers. During the positive phases of the PDO, the Indian Ocean SST is warmer than that during the negative phases of the PDO, and the enhanced convection and the associated heating drive a stronger anticyclone over the northwestern Pacific, leading to a stronger and westward extending WPSH, which is favorable for more heat waves over eastern China. Hence, the variable interannual WPSH-NHD variation is essentially a manifestation of a variable interannual ENSO-NHD connection through the Indian Ocean warming, which can be modulated by the phase changes of the PDO.

In addition, in this study the EEMD method is used to derive the interannual variability components of the time series. We acknowledge that the result is not method-dependent. For example, if we apply the simple normalization and detrending method as a filter, the correlation coefficient between the WPSH and NHD indices is 0.56 in the positive phase of the PDO, which is statistically significant at the $1 \%$ level, while the corresponding correlation coefficient is 0.26 in the negative phase of the PDO, which is statistically insignificant at the $5 \%$ and $10 \%$ levels. The results are hence qualitatively consistent with those based on the EEMD method, where the corresponding correlation coefficients are 0.65 and 0.12 , respectively.

We also acknowledge that the current study is based on composite analysis; while the composite analyses show strong evidences that the decadal variations in the WPSH-heat wave connection are modulated by the phase changes of PDO, the limited cases due to data availability may cause uncertainty. We hope to further examine the robustness of the composite analysis in the near future by diagnosing the output of freely coupled ocean-atmosphere model simulations that are hundreds of years long. In addition, based on our analysis, while we highlight that the tight (loose) WPSH-heat wave relation is forced by the stronger (weaker) Indian Ocean warming in El Niño decaying-year summers for the PDO positive (negative) phase, we should also acknowledge that the cooling in the tropical central-eastern Pacific associated with the negative phase of PDO might also be favorable to the eastward retreat of the WPSH based on the Matsuno-Gill theory. Numerical experiments are needed to examine the hypothesis in the future.

Acknowledgments. This research was supported by the National Natural Science Foundation of China (Grant 41330423) and the Jiangsu Collaborative Innovation Center for Climate Change. We are grateful to Dr. Xiaolong Chen from the Institute of Atmospheric Physics, Chinese Academy of Sciences, for helping us to draw Fig. 10 and providing helpful suggestions.

\section{REFERENCES}

Arblaster, J. M., and L. V. Alexander, 2012: The impact of the El Niño-Southern Oscillation on maximum temperature extremes. Geophys. Res. Lett., 39, L20702, https://doi.org/10.1029/ 2012GL053409.

Chen, X., and T. Zhou, 2018: Relative contributions of external SST forcing and internal atmospheric variability to July-August heat waves over the Yangtze River valley during 1979-2014. Climate Dyn., 51, 4403-4419, https://doi.org/10.1007/s00382-017-3871-y.

CMA, 2010: China Climate Bulletin for 2010. China Meteorological Administration, $15 \mathrm{pp}$.

_ 2013: China Climate Bulletin for 2013. China Meteorological Administration, 25 pp.

— 2016: China Climate Bulletin for 2016. China Meteorological Administration, 50 pp., http://www.cma.gov.cn/root7/auto13139/ 201705/t20170525_415102.html.

Ding, T., W. Qian, and Z. Yan, 2010: Changes in hot days and heat waves in China during 1961-2007. Int. J. Climatol., 30, 14521462, https://doi.org/10.1002/joc.1989.

Ding, Y. H., and J. C. L. Chan, 2005: The East Asian summer monsoon: An overview. Meteor. Atmos. Phys., 89, 117-142, https://doi.org/10.1007/s00703-005-0125-z.

Duchon, C., 1979: Lanczos filtering in one and two dimensions. J. Appl. Meteor., 18, 1016-1022, https://doi.org/10.1175/ 1520-0450(1979)018<1016:LFIOAT > 2.0.CO;2. 
Feng, J., L. Wang, and W. Chen, 2014: How does the East Asian summer monsoon behave in the decaying phase of El Niño during different PDO phases? J. Climate, 27, 2682-2698, https://doi.org/10.1175/JCLI-D-13-00015.1.

Folland, C. K., J. A. Renwick, M. J. Salinger, and A. B. Mullan, 2002: Relative influences of the interdecadal Pacific oscillation and ENSO on the South Pacific convergence zone. Geophys. Res. Lett., 29, 1643, https://doi.org/10.1029/2001GL014201.

García-Herrera, R., J. Díaz, R. M. Trigo, J. Luterbacher, and E. M. Fischer, 2010: A review of the European summer heat wave of 2003. Crit. Rev. Environ. Sci. Technol., 40, 267-306, https:// doi.org/10.1080/10643380802238137.

Gill, A. E., 1980: Some simple solutions for heat-induced tropical circulation. Quart. J. Roy. Meteor. Soc., 106, 447-462, https:// doi.org/10.1002/qj.49710644905.

He, C., T. Zhou, A. Lin, B. Wu, D. Gu, C. Li, and B. Zheng, 2015: Enhanced or weakened western North Pacific subtropical high under global warming? Sci. Rep., 5, 16771, https://doi.org/ $10.1038 /$ srep16771.

Huang, N. E., and Z. Wu, 2008: A review on Hilbert-Huang transform: Method and its applications to geophysical studies. Rev. Geophys., 46, RG2006, https://doi.org/10.1029/2007RG000228.

— , and Coauthors, 1998: The empirical mode decomposition and the Hilbert spectrum for nonlinear and non-stationary time series analysis. Proc. Roy. Soc. London, 454A, 903-995, https:// doi.org/10.1098/rspa.1998.0193.

Kalnay, E., and Coauthors, 1996: The NCEP/NCAR 40-Year Reanalysis Project. Bull. Amer. Meteor. Soc., 77, 437-471, https:// doi.org/10.1175/1520-0477(1996)077<0437:TNYRP>2.0.CO;2.

Kosaka, Y., J. S. Chowdary, S.-P. Xie, Y. M. Min, and J. Y. Lee, 2012: Limitations of seasonal predictability for summer climate over East Asia and the northwestern Pacific. J. Climate, 25, 7574-7589, https://doi.org/10.1175/JCLI-D-12-00009.1.

- , S.-P. Xie, N.-C. Lau, and G. A. Vecchi, 2013: Origin of seasonal predictability for summer climate over the northwestern Pacific. Proc. Natl. Acad. Sci. USA, 110, 7574-7579, https:// doi.org/10.1073/pnas.1215582110.

Lau, N.-C., and M. J. Nath, 2003: Atmosphere-ocean variations in the Indo-Pacific sector during ENSO episodes. J. Climate, 16, 3-20, https://doi.org/10.1175/1520-0442(2003)016<0003: AOVITI $>2.0 . \mathrm{CO} ; 2$

- , and B. Wang, 2006: Interactions between Asian monsoon and the El Niño-Southern Oscillation. The Asian Monsoon, B. Wang, Ed., Springer/Praxis Publishing, 478-512.

Li, D., T. Zhou, L. Zou, W. Zhang, and L. Zhang, 2018a: Extreme high-temperature events over East Asia in $1.5^{\circ} \mathrm{C}$ and $2^{\circ} \mathrm{C}$ warmer futures: Analysis of NCAR CESM low-warming experiments. Geophys. Res. Lett., 45, 1541-1550, https://doi.org/ 10.1002/2017GL076753.

- L. Zou, and T. Zhou, 2018b: Regional air-sea coupled model simulation for two types of extreme heat in North China. Climate Dyn., 50, 2107-2120, https://doi.org/10.1007/ s00382-017-3738-2.

,-- , and,$- 2018 \mathrm{c}$ : Extreme climate event changes in China in $1.5^{\circ} \mathrm{C}$ and $2^{\circ} \mathrm{C}$ warmer climates: Results from statistical and dynamical downscaling. J. Geophys. Res. Atmos., 123, 10215-10 230, https://doi.org/10.1029/2018JD028835.

Li, H., A. Dai, T. Zhou, and J. Lu, 2010: Responses of East Asian summer monsoon to historical SST and atmospheric forcing during 1950-2000. Climate Dyn., 34, 501-514, https://doi.org/ 10.1007/s00382-008-0482-7.

Li, J., T. Ding, X. L. Jia, and X. C. Zhao, 2015: Analysis on the extreme heat wave over China around Yangtze River region in the summer of 2013 and its main contributing factors. $A d v$. Meteor., 2015, 706713, https://doi.org/10.1155/2015/706713.

Li, Q., X. Liu, H. Zhang, T. C. Peterson, and D. T. Easterling, 2004: Detecting and adjusting temporal inhomogeneity in Chinese mean surface air temperature data. Adv. Atmos. Sci., 21, 260 268, https://doi.org/10.1007/BF02915712.

Li, S. L., J. Lu, G. Huang, and K. Hu, 2008: Tropical Indian Ocean basin warming and East Asian summer monsoon: A multiple AGCM study. J. Climate, 21, 6080-6088, https://doi.org/ 10.1175/2008JCLI2433.1.

Li, T., B. Wang, B. Wu, T. Zhou, C.-P. Chang, and R. Zhang, 2017: Theories on formation of an anomalous anticyclone in western north Pacific during El Niño: A review. J. Meteor. Res., 31, 987-1006, https://doi.org/10.1007/s13351-017-7147-6.

Li, W. H., L. F. Li, M. F. Ting, and Y. M. Liu, 2012: Intensification of Northern Hemisphere subtropical highs in a warming climate. Nat. Geosci., 5, 830-834, https://doi.org/10.1038/ngeo1590.

Liebmann, B., and C. A. Smith, 1996: Description of a complete (interpolated) outgoing longwave radiation dataset. Bull. Amer. Meteor. Soc., 77, 1275-1277.

Luber, G., and M. McGeehin, 2008: Climate change and extreme heat events. Amer. J. Prev. Med., 35, 429-435, https://doi.org/ 10.1016/j.amepre.2008.08.021.

Ma, S., T. Zhou, D. A. Stone, O. Angélil, and H. Shiogama, 2017: Attribution of the July-August 2013 heat event in central and eastern China to anthropogenic greenhouse gas emissions. Environ. Res. Lett., 12, 054020, https://doi.org/10.1088/1748-9326/ aa69d2.

Mantua, N. J., S. R. Hare, Y. Zhang, J. M. Wallace, and R. C. Francis, 1997: A Pacific interdecadal climate oscillation with impacts on salmon production. Bull. Amer. Meteor. Soc., 78, 1069-1079, https://doi.org/10.1175/1520-0477(1997)078<1069: APICOW $>2.0 . C O ; 2$.

Matsuno, T., 1966: Quasi-geostrophic motions in the equatorial area. J. Meteor. Soc. Japan, 44, 25-43, https://doi.org/10.2151/ jmsj1965.44.1_25.

Meehl, G. A., and C. Tebaldi, 2004: More intense, more frequent, and longer lasting heat waves in the 21 st century. Science, $\mathbf{3 0 5}$, 994-997, https://doi.org/10.1126/science.1098704.

Park, C. K., and S. D. Schubert, 1997: On the nature of the 1994 East Asian summer drought. J. Climate, 10, 10561070, https://doi.org/10.1175/1520-0442(1997)010<1056: OTNOTE $>2.0 . \mathrm{CO} ; 2$.

Power, S., T. Casey, C. Folland, A. Colman, and V. Mehta, 1999: Inter-decadal modulation of the impact of ENSO on Australia. Climate Dyn., 15, 319-324, https://doi.org/10.1007/ s003820050284.

Qian, C., and T. Zhou, 2014: Multidecadal variability of North China aridity and its relationship to PDO during 19002010. J. Climate, 27, 1210-1222, https://doi.org/10.1175/ JCLI-D-13-00235.1.

Santer, B. D., and Coauthors, 2005: Amplification of surface temperature trends and variability in the tropical atmosphere. Science, 309, 1551-1556, https://doi.org/10.1126/science.1114867.

Smith, T. M., R. W. Reynolds, T. C. Peterson, and J. Lawrimore, 2008: Improvements to NOAA's historical merged landocean surface temperature analysis (1880-2006). J. Climate, 21, 2283-2296, https://doi.org/10.1175/2007JCLI2100.1.

Song, F., and T. Zhou, 2014: Interannual variability of East Asian summer monsoon simulated by CMIP3 and CMIP5 AGCMs: Skill dependence on Indian Ocean-western Pacific anticyclone teleconnection. J. Climate, 27, 1679-1697, https://doi.org/10.1175/ JCLI-D-13-00248.1. 
and -2015 : The crucial role of internal variability in modulating the decadal variation of the East Asian summer monsoonENSO relationship during the twentieth century. J. Climate, 28, 7093-7107, https://doi.org/10.1175/JCLI-D-14-00783.1.

Sun, Y., X. Zhang, F. Zwiers, L. Song, H. Wan, T. Hu, H. Ying, and G. Ren, 2014: Rapid increase in the risk of extreme summer heat in eastern China. Nat. Climate Change, 4, 1082-1085, https://doi.org/10.1038/nclimate2410.

Tao, S. Y., and L. X. Chen, 1987: A review of recent research on the East Asian summer monsoon in China. Monsoon Meteorology, C. P. Chang, and T. N. Krishnamurti, Eds., Oxford University Press, 60-92.

Trenberth, K., and L. Smith, 2006: The vertical structure of temperature in the tropics: Different flavors of El Niño. J. Climate, 19, 4956-4973, https://doi.org/10.1175/JCLI3891.1.

- D. P. Stepaniak, and L. Smith, 2005: Interannual variability of the patterns of atmospheric mass distribution. J. Climate, $\mathbf{1 8}$, 2812-2825, https://doi.org/10.1175/JCLI3333.1.

Wang, B., R. Wu, and X. Fu, 2000: Pacific-East Asian teleconnection: How does ENSO affect East Asian climate? J. Climate, 13, 1517-1536, https://doi.org/10.1175/1520-0442(2000)013<1517: PEATHD $>2.0 . \mathrm{CO} ; 2$

Wang, L., W. Chen, and R. Huang, 2008: Interdecadal modulation of PDO on the impact of ENSO on the East Asian winter monsoon. Geophys. Res. Lett., 35, L20702, https://doi.org/10.1029/ 2008GL035287.

Wang, P., J. Tang, S. Wang, X. Dong, and J. Fang, 2018: Regional heatwaves in China: A cluster analysis. Climate Dyn., 50, 1901-1917, https://doi.org/10.1007/s00382-017-3728-4.

Wang, W., W. Zhou, X. Li, X. Wang, and D. Wang, 2016: Synopticscale characteristics and atmospheric controls of summer heat waves in China. Climate Dyn., 46, 2923-2941, https://doi.org/ 10.1007/s00382-015-2741-8.

Wang, Y., B. Wang, and J. H. Oh, 2001: Impact of the preceding El Niño on the East Asian summer atmosphere circulation. J. Meteor. Soc. Japan, 79, 575-588, https://doi.org/10.2151/ jmsj.79.575.

Wu, B., T. Zhou, and T. Li, 2009: Seasonally evolving dominant interannual variability modes of East Asian climate. J. Climate, 22, 2992-3005, https://doi.org/10.1175/2008JCLI2710.1.
Wu, Z. H., and N. E. Huang, 2009: Ensemble empirical mode decomposition: A noise-assisted data analysis method. Adv. Adapt. Data Anal., 1, 1-41, https://doi.org/10.1142/S1793536909000047.

Wu, Z. W., P. Zhang, H. Chen, and Y. Li, 2016: Can the Tibetan Plateau snow cover influence the interannual variations of Eurasian heat wave frequency? Climate Dyn., 46, 3405-3417, https://doi.org/10.1007/s00382-015-2775-y.

Xie, S.-P., K. Hu, J. Hafner, H. Tokinaga, Y. Du, G. Huang, and T. Sampe, 2009: Indian Ocean capacitor effect on Indo-western Pacific climate during the summer following El Niño. J. Climate, 22, 730-747, https://doi.org/10.1175/2008JCLI2544.1.

—, Y. Du, G. Huang, X. T. Zheng, H. Tokinaga, K. Hu, and Q. Liu, 2010: Decadal shift in El Niño influences on Indowestern Pacific and East Asian climate in the 1970s. J. Climate, 23, 3352-3368, https://doi.org/10.1175/2010JCLI3429.1.

Yang, J. L., Q. Y. Liu, S. P. Xie, Z. Y. Liu, and L. X. Wu, 2007: Impact of the Indian Ocean SST basin mode on the Asian summer monsoon. Geophys. Res. Lett., 34, L02708, https://doi. org/10.1029/2006GL028571.

Zhou, T., and J. Zhang, 2011: The vertical structures of atmospheric temperature anomalies associated with two flavors of El Niño simulated by AMIP II models. J. Climate, 24, 10531070, https://doi.org/10.1175/2010JCLI3504.1.

_ - R. Yu, H. Li, and B. Wang, 2008: Ocean forcing to changes in global monsoon precipitation over the recent halfcentury. J. Climate, 21, 3833-3852, https://doi.org/10.1175/ 2008JCLI2067.1.

—_, and Coauthors, 2009a: Why the western Pacific subtropical high has extended westward since the late 1970s. J. Climate, 22, 2199-2215, https://doi.org/10.1175/2008JCLI2527.1.

—, D. Gong, J. Li, and B. Li, 2009b: Detecting and understanding the multi-decadal variability of the East Asian summer monsoon? Recent progress and state of affairs. Meteor. Z., 18, 455-467, https://doi.org/10.1127/0941-2948/ 2009/0396.

_ - S. Ma, and L. Zou, 2014: Understanding a hot summer in central eastern China: Summer 2013 in context of multi-model trend analysis [in "Explaining Extreme Events of 2013 from a Climate Perspective"]. Bull. Amer. Meteor. Soc., 95, S54-S57, https://doi.org/10.1175/1520-0477-95.9.S1.1. 